\title{
Research on Teaching Ideas and Teaching Methods of Flying Students' "World History"
}

\author{
Zhuoqi Li \\ Department of Humanities and Social Sciences, Aviation Foundation College, Air Force \\ Aeronautical University,Changchun, Jilin 130022, China \\ 1064048566@qq.com
}

\section{Key words: Flying Cadets;World history;Teaching idea;Teaching method}

\begin{abstract}
World History Essentials is a compulsory course for pilots set up by Air Force Aeronautics University, which plays an important role in the quality education of pilots. A complete teaching model including "pre-class teaching analysis" to "teaching guiding ideology" and "teaching methods" has been formed in the teaching process. It has achieved good teaching results.
\end{abstract}

\section{Course Introduction}

The World History Synopsis course is a compulsory examination course offered by the Air Force Aviation University of our university for the students majoring in aviation flight and command officer education[1].It is offered in the second semester of their sophomore year and lasts 20 hours. In the "Personnel Training Program" it is under the science and culture curriculum module, but also our school for flying cadets to open one of the five humanities compulsory courses. It plays an important role in promoting students'cultural accomplishment, improving their humanistic quality, shaping their noble personality, and cultivating high-quality new military personnel for national defense construction. Therefore, from the perspective of the status of the curriculum, "World History Synopsis" belongs to the core basic course of humanistic quality education[2].

Around the core of humanistic quality cultivation, curriculum teaching objectives are defined as three levels: knowledge objectives, namely, through curriculum learning, to grasp the main thread of the rise and development of the capitalist world, to be familiar with the important historical events in modern world history, to understand its historical significance, and to understand the causes and backgrounds of its occurrence;Ability goal is to cultivate the students'ability to study independently and think independently through the course study, learn to use the standpoints, viewpoints and methods of historical materialism and dialectical materialism to understand and analyze historical problems, understand the culture of other countries, understand the laws of history, draw lessons from historical experience, draw historical wisdom, and establish Correct conception of history and world outlook;Emotional goals are to establish a life attitude that is concerned about the fate of the nation and the fate of the nation and the development trend of the world through curriculum learning; to establish the awareness of promoting the humanistic quality, to establish a correct outlook on life and values; to cultivate patriotic feelings, to enhance the sense of national identity and historical mission, and to contribute to national defense construction. The three are complementary and indispensable[3].

\section{Pre class teaching analysis}

In order to achieve the above teaching objectives, we should make adequate pre class teaching preparations, including:

The status of trainees was analyzed. The first is the analysis of cultural quality. The students are all students who have taken the college entrance examination more than one line. They have been studying in our university for nearly two years. Therefore, they basically possess the cultural quality of the sophomore year. The two is the analysis of personality characteristics. The students are all post-90s, and they are in the period of 1998-99. They are generally flexible, active and self-conscious. There are obvious personal preferences for the course of World History. According 
to the pre-class questionnaire survey, nearly $70 \%$ of the students are interested in world history and think it is necessary to study this course. However, some students did not realize the importance of learning the course of world history. The three is learning experience analysis. Students received world history education in secondary school, but the degree of education was different. Most of the students are science students, accounting for $90 \%$, with a certain amount of historical knowledge, but not rich enough, comparative basis, liberal arts students accounted for $10 \%$, historical knowledge reserve is relatively rich[4].

In view of the characteristics of such students, teachers are required to pay attention to the following three problems in teaching: first, avoid repetitive teaching, distinguish higher education from secondary education, reflecting the characteristics of higher education. The second is to take into account the learning needs of different basic students, the teaching level is clear, and effectively achieve the purpose of imparting knowledge, training ability and improving quality. Thirdly, in view of some students'weariness, laziness and unclear understanding of the purpose of learning, we should focus on improving students' interest in learning and helping them understand the value of history learning[5].

The teaching material system is analyzed. This course uses the handouts of World History Synopsis, a self-compiled textbook. It is written by the World History Teachers of the History Department of our university in different chapters, totaling 150,000 words. There are two characteristics in teaching materials: first, modern history. The history of the world over 7000 years can be divided into ancient history, medieval history, modern history and modern history according to time, but the class hour is only 20 hours, which determines that our teaching can not be general history education, can not be all-inclusive, therefore, we must have a choice of historical materials. How can we accept the purpose of the "world history"? After discussion, it is finally determined that the rise and development of the capitalist world is the main thread, that is, the choice of modern history as the main content of the textbook.The teaching material system is analyzed. This course uses the handouts of World History Synopsis, a self-compiled textbook. It is written by the World History Teachers of the History Department of our university in different chapters, totaling 150,000 words. There are two characteristics in teaching materials: first, modern history. The history of the world over 7000 years can be divided into ancient history, medieval history, modern history and modern history according to time, but the class hour is only 20 hours, which determines that our teaching can not be general history education, can not be all-inclusive, therefore, we must have a choice of historical materials. How can we accept the purpose of the "world history"? After discussion, it is finally determined that the rise and development of the capitalist world is the main thread, that is, the choice of modern history as the main content of the textbook.[1]

The teaching material system is analyzed. This course uses the handouts of World History Synopsis, a self-compiled textbook. It is written by the World History Teachers of the History Department of our university in different chapters, totaling 150,000 words. There are two characteristics in teaching materials: first, modern history. The history of the world over 7000 years can be divided into ancient history, medieval history, modern history and modern history according to time, but the class hour is only 20 hours, which determines that our teaching can not be general history education, can not be all-inclusive, therefore, we must have a choice of historical materials. How can we accept the purpose of the "world history"? After discussion, it is finally determined that the rise and development of the capitalist world is the main thread, that is, the choice of modern history as the main content of the textbook.

\section{Teaching guiding ideology}

The guiding ideology of this course is determined by considering three factors: first, from the top-level design point of view, as the core basic course of the humanistic quality training of flight cadets, the teaching guiding ideology must proceed from the humanistic quality training needs of flight cadets, that is, to cultivate the lofty humanistic feelings ,thick humanistic interest, rich humanistic knowledge and healthy humanistic style; second, from the perspective of educational law, teaching guiding ideology must conform to the characteristics of history. Firstly, it has a large 
span of time, a wide space coverage and a wide range of complex contents; secondly, it has the characteristics of foundation, comprehensiveness and humanism; thirdly, it has the natural educational function of learning from history;third, from the perspective of teaching implementation, the teaching guiding ideology must consider the characteristics of teaching objects.All the students were born after 1998. They were all students above the first line of the college entrance examination. They were generally flexible in mind and active in thought.But the students are mainly science subjects, with less historical knowledge.

Based on the above three considerations, our teaching guidelines can be summarized as three points, namely, three "degrees": first, to expand the scope of teaching. One is to try to transfer more knowledge to the students in limited class hours; the other is to pay attention to the integration of multi-disciplinary knowledge. For example, geographic knowledge, military knowledge, common sense of Sinology into teaching, to help students understand history more scientifically and comprehensively.For example, in the lesson "Early Civilization and Its Development", when comparing the difference between Sumerian civilization and ancient Egyptian civilization, we can not do without the introduction and analysis of the geographical environment characteristics of the birthplace of the two civilizations. For example, in the two classes of "World War I" and "World War II", the introduction of typical weapons and equipment, military theory and famous generals is indispensable.Second, deepen teaching depth. This is the key to the difference between higher education and secondary school teaching.Secondary school education pays attention to solving the "what" problem, and higher education pays attention to solving the "why" problem, that is, to change "heavy memory" to "heavy thinking".For example, the lesson "Achievements in Soviet Socialist Initial Construction" does not focus on students remembering what achievements the Soviet Union has made, but on students summing up experience and lessons from the socialist construction of the Soviet Union, drawing historical wisdom, and understanding the important implications of Soviet Union's construction experience for China's socialist construction. Guided and referential significance, the extension of teaching depth is achieved;Third, improve teaching temperature. The first is to fully apply the historical stories and interesting to teaching to stimulate students'interest in learning; the second is to combine knowledge teaching with emotional education, will quality education and values education to give full play to the function of the core basic courses of humanistic quality education.For example, in the course of "New Route Opening", in addition to the historical process, the spirit of adventure, the spirit of seeking knowledge and perseverance of Western navigators are also the beliefs and perseverance pilots should learn from. In addition, we recombed the way of communication between the East and the West in history. From Zhang Qian's extradition to the western region, to the prosperity of the ancient Silk Road, to the opening of the new route and the colonial expansion of the west, to the policy of "one belt and one road" proposed by President Xi in 2013, we brought the nineteen spirits and the important ideas of President Xi into the classroom. We should carry out patriotic education for students in order to achieve the goal of emotional education.

\section{Teaching methods and means}

According to the characteristics of history, we still use classroom teaching as the main teaching method, and flexibly use other forms, such as research and discussion, organizing debates and other forms to cultivate students'autonomous learning ability[6].

Classroom teaching mainly follows the "four look teaching method",that is,far look,overlooking, close observation and scrutiny. This is a teaching method that follows the rules of history teaching.Looking far and far, first of all, students will be brought into the big historical era, feel the historical atmosphere, into the historical background, into the historical state;Overlooking is to look down from a higher platform, to locate the status and importance of historical events in the historical era, and to help students control the overall situation of historical events;Close observation, we will introduce the whole process of historical events to the trainees, restore the historical truth and pursue the truth of history;Scrutiny, guide the students to understand and reflect on the significance of historical events and the underlying causes, to understand the laws of 
history.For example, the lesson of World War I begins with the background of the 20th century, when the people of Europe were enjoying the great improvement of productivity and living standards brought about by the Industrial Revolution, the war broke out suddenly and the theme of the 20th century became war. The second bird's eye view of the overall situation of World War I, from the overall understanding of the duration of World War I, the scope of the war, the number of people involved in the war, casualties, economic losses caused, etc. Third, a close look at the whole process of World War I, to understand the classic battles in World War I, important signs and turning points, representatives and so on; and finally, a careful examination, including understanding of the nature of World War I, the outbreak of World War I. The reason for this is to understand the development rule of the capitalist world and reflect on the tremendous influence of war on mankind.

According to the characteristics of teaching content, we can also flexibly apply various teaching methods.For example, the debate teaching method.Taking the lesson of the American Revolution as an example, the debate teaching method can be adopted. As for the American War of Independence, the traditional view is that it is a war of national liberation, but there is another voice in the history circle, that is, it is a civil war of the British Empire. So the instructors set the topic of debate, "Is the American Revolution a war of national liberation or a war of secession". The students were arranged in advance to prepare for the debate. The students themselves searched for information, prepared arguments and signed up to participate in the debate. Four debaters from both sides were selected for the contest. The debate process was organized and implemented by the chairman of the contest selected by the participants. The rest of the participants voted on both sides of the debate as judges and elected the winning team after the debate.Firstly, it is helpful to stimulate students'enthusiasm for learning and cultivate their autonomous learning ability, thus realizing the flipped classroom teaching with students as the main part and teachers as the supplement, which is very popular with students. Secondly, it can help the students to have a more comprehensive understanding and grasp of this history, to understand the diverse ideas of the academic community, and to broaden their horizons. Thirdly, it can also arouse the students to think more deeply and cultivate the ability of dialectical thinking in the collision of different viewpoints.

\section{References}

[1] C.Y. Bi: Lecture notes on world history (Air Force Aviation University,China 2014)(In Chinese)

[2] M. Jiang and Y.G. Mu: Quality education for flying cadets (Jilin People' s Press,China 2012)(In Chinese)

[3] C.L.Zhang: Chinese Teaching Communication, (2012) No.10, p.83-85.(In Chinese)

[4] G.J. Yang,and Q.S. Zhang:Modern Educational Science, (2009) No.S1, p.86-87.(In Chinese)

[5] Y. Min,J.Y. Zhang and M.X. Huang: Science and wealth, (2015) No.10, p.334.(In Chinese)

[6] J. Yu:Examination Weekly, (2018) No.13, p.151.(In Chinese)

[7] D.M. Zhou: Motherland, (2017) No.24, p.250.(In Chinese) 